\title{
Extraterrestrial Influences on Remote Sensing in the Earth's Atmosphere
}

\author{
Aleksandra Nina ${ }^{1, *(\mathbb{D})}$, Milan Radovanović ${ }^{2,3}$ (D) and Luka Popović $4,5,6$ (D) \\ 1 Institute of Physics Belgrade, University of Belgrade, 11080 Belgrade, Serbia \\ 2 Geographical Institute "Jovan Cvijić” SASA, 11000 Belgrade, Serbia; m.radovanovic@gi.sanu.ac.rs \\ Institute of Sports, Tourism and Service, South Ural State University, 454080 Chelyabinsk, Russia \\ Astronomical Observatory, 11060 Belgrade, Serbia; lpopovic@aob.rs \\ 5 Department of Astronomy, Faculty of mathematics, University of Belgrade, 11000 Belgrade, Serbia \\ 6 Faculty of Science, University of Banja Luka, 78000 Banja Luka, Republic of Srpska, Bosnia and Herzegovina \\ * Correspondence: sandrast@ipb.ac.rs
}

check for updates

Citation: Nina, A.; Radovanović, M.; Popović, L. Extraterrestrial Influences on Remote Sensing in the Earth's Atmosphere. Remote Sens. 2021, 13, 890. https://doi.org/10.3390/ rs13050890

Received: 17 February 2021

Accepted: 22 February 2021

Published: 26 February 2021

Publisher's Note: MDPI stays neutral with regard to jurisdictional claims in published maps and institutional affiliations.

Copyright: (c) 2021 by the authors. Licensee MDPI, Basel, Switzerland. This article is an open access article distributed under the terms and conditions of the Creative Commons Attribution (CC BY) license (https:/ / creativecommons.org/licenses/by/ $4.0 /)$.
Abstract: Atmospheric properties have a significant influence on electromagnetic (EM) waves, including the propagation of EM signals used for remote sensing. For this reason, changes in the received amplitudes and phases of these signals can be used for the detection of the atmospheric disturbances and, consequently, for their investigation. Some of the most important sources of the temporal and space variations in the atmospheric parameters come from the outer space. Although the solar radiation dominates in these processes, radiation coming out of the solar system also can induces enough intensive disturbance in the atmosphere to provide deflections in the EM signal propagation paths. The aim of this issue is to present the latest research linking events and processes in outer space with changes in the propagation of the satellite and ground-based signals used in remote sensing.

Keywords: atmosphere; observations; signal processing; modelling; extraterrestrial radiation; solar radiation; disturbances; remote sensing

\section{Introduction}

As the highest terrestrial layer, the atmosphere is under permanent influences from outer space. For this reason and due to link with many processes in different areas of Earth, the temporal and space distributions of atmospheric parameters are very complex and have been the focus of a number of studies in different research fields. The application of these studies is important for pure sciences but also for applied sciences and technology.

Since the measurement of atmospheric parameters using on-site methods is very complex, remote sensing has very important role in observations of different-altitude domains. The propagation properties of a signal which have been used for different kinds of remote sensing depend on the different atmospheric parameters, such as the electron density and temperature. The spatial and temporal variations in these parameters affect signal propagations and, consequently, the corresponding applications of the used technique, such as observations and positioning. Some of the most important sources of atmospheric disturbances are solar wind and radiation. In addition, cosmic rays can provide intensive perturbations of the outer Earth's layer [1-3]. The perturbation intensity, duration, and location in the Earth's atmosphere can be quite different, which can induce various signal deviations.

The focus of this Special Issue is: (1) the detection of extraterrestrial events and induced atmospheric disturbance modelling, and (2) the influences of atmospheric parameter variations on EM signal propagation. 


\section{Extraterrestrial Influences on the Earth Atmosphere-Remote Sensing of Disturbances}

The properties of the atmospheric disturbances induced by extraterrestrial events and processes depend on the characteristics of the disturbance sources (intensities, source type etc.), the considered atmospheric area (due to interaction of incoming radiation or bodies with particles within them), and the space between them (due to the interaction of incoming radiation or bodies with the atmosphere part before its arrival at the considered location). Charged particlesprimarily disturb the upper ionosphere as well as the polar and near-polar latitudes (due to the geomagnetic field), while the influence of the EM radiation depends on the radiation intensity, wavelength, impact angle in the atmosphere, and the area within its propagation.

These variations can be periodical because of, for example, variations during a solar cycle, year (due to Earth's revolution), and day (due to Earth's rotation), and sudden due to expected or unexpected outer space phenomena (see Figure 1). The periodical changes in the atmospheric parameters and the precision of their determination are primarily connected with the solar radiation. They are recorded within all atmospheric layers, from the ionosphere and magnetosphere in the upper atmosphere [4-6] to the troposphere and stratosphere in the lower atmosphere [7]. The sources of these sudden perturbations can be the Sun, solar system, galaxy, or the wider Universe [3,8]. The intensity and duration of their influences on the atmosphere are different: from very weak and very hard to detect to extremely intensive when the atmospheric parameters are changed by several orders of magnitude [9,10], and from short-lasting (several milliseconds) [2] to perturbations of several days or more [11].

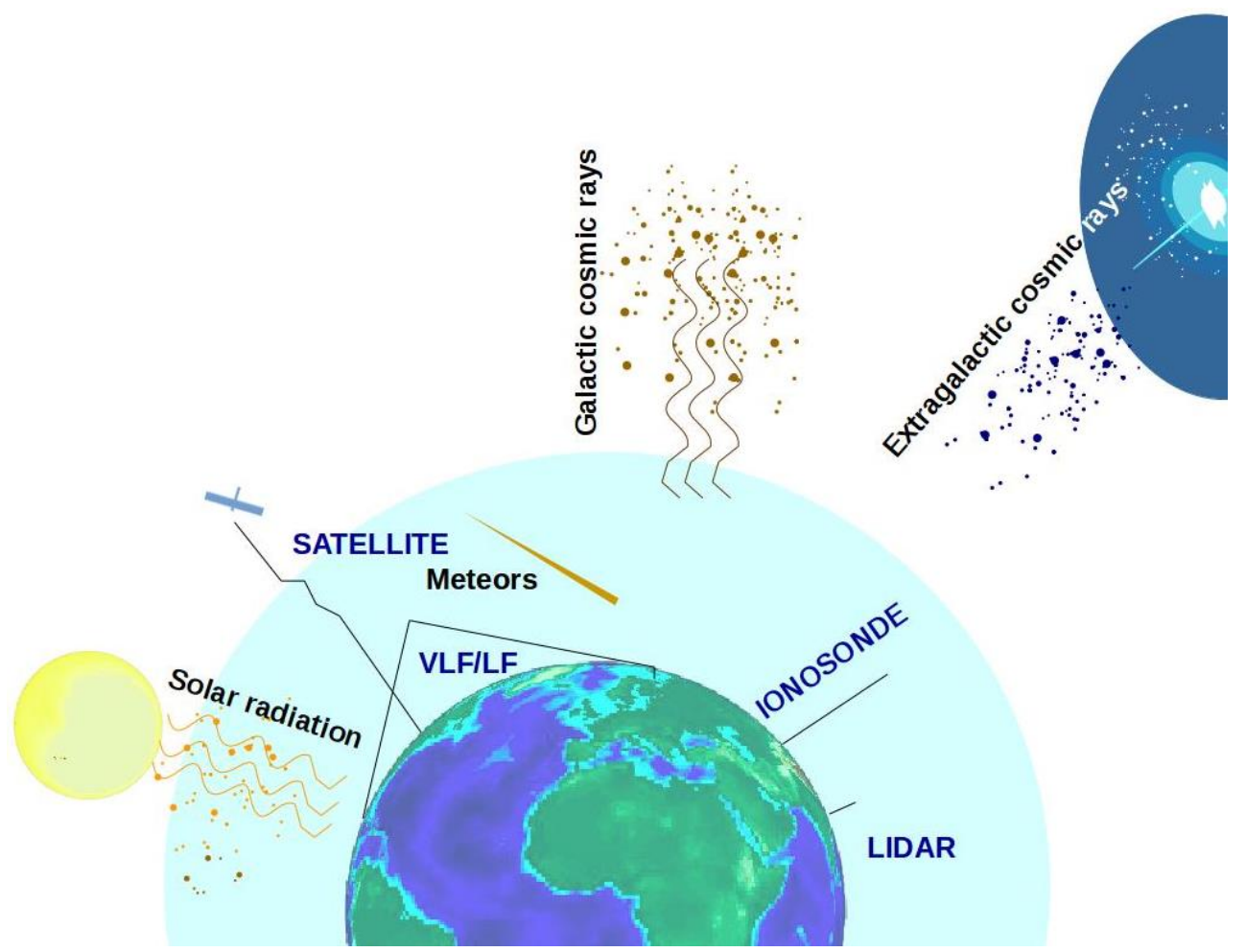

Figure 1. Scheme of outer space's influence on the Earth's atmosphere. Extraterrestrial electromagnetic and particle radiation coming from the Sun, our galaxy, and the wider universe, and impact of meteors in the Earth's atmosphere. Several examples of the remote sensing of the atmosphere: troposphere observations by LIDAR, VLF/LF signal monitoring of the lower ionosphere, ionospheric monitoring using signals emitted by ionosondes, satellite observations.

The application of an observation technique depends on the considered altitude domain. In addition, the detection of the short-term variations requires the good temporal 
resolution of the observed data, while the monitoring of the unpredictable phenomena is possible with continuous measurements provided by, for example, the Global Navigation Satellite System (GNSS) [12] or lower ionosphere monitoring by very low /low frequency radio waves $[2,3,13,14]$.

The recorded data are included in many methodologies for the modelling of the spatial and temporal distributions of atmospheric parameters. In some cases, their estimation within a local area require a more then one data set and more than one monitoring techniques [15-17] which provides more precious estimates of atmospheric properties.

\section{Extraterrestrial Influences on Electromagnetic Signal Propagation}

The investigation of the signal propagation changes induced by extraterrestrial events and processes, primarily with origins in the solar system, is very important due to possible errors in their use in observations and modelling. This task can be crucial for precision in technologies based on, for example, satellite signal propagation, which is reason why the corresponding research took place many decades ago and why it is still of high importance.

In this field, solar radiation is the subject of most relevant studies. Its influence on satellite signals dominates in the upper ionosphere due to the largest electron density in this atmospheric layer, which is often used as an approximation in the estimation of the total electron content (TEC), the ionospheric parameter required in the modelling of signal propagation [18-20]. However, the recent study presented in [21] shows that errors due to the neglect of the D-region electron density increase induced by a solar X-ray flare can be important for the precision of satellite signal propagation modelling. Lower ionosphere disturbances as well as F-region disturbances below the altitude of the electron density maximum are important for the propagation of ground-based signals emitted at the surface and reflected from the ionosphere. A well-known example of extreme solar radiation influence on radio signal propagation is black out [22].

The influence of the Solar radiation on the quality of signals is also reported in lower atmospheric observations. As an example, in [23] the authors analysed solar radiation's influence on error in temperature measurements.

\section{Summary}

The main goal of this Special Issue is to collect studies about extraterrestrial influences on remote sensing in the Earth's atmosphere. Attention is focused on research on the following topics:

- The detection of extra-terrestrial radiation and the modelling of the induced atmospheric disturbances using different kinds of remote sensing techniques;

- Changes in signals used for remote sensing and the quality of their applications during influences of extra-terrestrial events;

- Influence of events from outer space on the detection of terrestrial or extra-terrestrial events and corresponding modelling, such as masking less intense perturbations with solar influences;

- The Earth's atmosphere's perturbations due to extra-terrestrial events (e.g., meteor perturbations) that may affect signal propagation, etc.

Studies in different research fields should emphasise the multidisciplinary character of both observations and modelling corresponding to extraterrestrial influences on remote sensing in the Earth's atmosphere

Author Contributions: Conceptualization, original draft preparation, and visualization, A.N.; review and editing, all authors. All authors have read and agreed to the published version of the manuscript.

Funding: The authors acknowledge funding provided by the Institute of Physics Belgrade and the Astronomical Observatory (the contract 451-03-68/2020-14/200002) through the grants by the Ministry of Education, Science, and Technological Development of the Republic of Serbia. 
Acknowledgments: The authors thank to Zoran Mijić and Nikola Veselinović for help in preparation of this paper, and Srđan Mitrović for help in promotion of this Special Issue. We also would like to thank the Remote Sensing editorial team for its support in preparation of this SI.

Conflicts of Interest: The authors declare no conflict of interest.

\section{References}

1. Siingh, D.; Singh, R. The role of cosmic rays in the Earth's atmospheric processes. Pramana J. Phys. 2010, 74, 153-168. [CrossRef]

2. Nina, A.; Simić, S.; Srećković, V.A.; Popović, L.Č. Detection of short-term response of the low ionosphere on gamma ray bursts. Geophys. Res. Lett. 2015, 42, 8250-8261. [CrossRef]

3. Inan, U.S.; Lehtinen, N.G.; Moore, R.C.; Hurley, K.; Boggs, S.; Smith, D.M.; Fishman, G.J. Massive disturbance of the daytime lower ionosphere by the giant $\gamma$-ray flare from magnetar SGR 1806-20. Geophys. Res. Lett. 2007, 34, 8103. [CrossRef]

4. Jerez, G.O.; Hernández-Pajares, M.; Prol, F.S.; Alves, D.B.M.; Monico, J.F.G. Assessment of Global Ionospheric Maps Performance by Means of Ionosonde Data. Remote Sens. 2020, 12, 3452. [CrossRef]

5. Lühr, H.; Maus, S. Solar cycle dependence of quiet-time magnetospheric currents and a model of their near-Earth magnetic fields. Earth Planets Space 2010, 62, 14. [CrossRef]

6. Nina, A.; Nico, G.; Mitrović, S.T.; Čadež, V.M.; Milošević, I.R.; Radovanović, M.; Popović, L.Č. Quiet Ionospheric D-Region (QIonDR) Model Based on VLF/LF Observations. Remote Sens. 2021, 13, 483. [CrossRef]

7. Wiencke, L.; Rizi, V.; Will, M.; Allen, C.; Botts, A.; Calhoun, M.; Carande, B.; Claus, J.; Coco, M.; Emmert, L.; et al. Joint elastic side-scattering LIDAR and Raman LIDAR measurements of aerosol optical properties in south east Colorado. J. Instrum. 2017, 12, P03008. [CrossRef]

8. Tsurutani, B.T.; Verkhoglyadova, O.P.; Mannucci, A.J.; Lakhina, G.S.; Li, G.; Zank, G.P. A brief review of "solar flare effects" on the ionosphere. Radio Sci. 2009, 44, 1. [CrossRef]

9. Singh, A.K.; Singh, A.; Singh, R.; Singh, R. Solar flare induced D-region ionospheric perturbations evaluated from VLF measurements. Astrophys. Space Sci. 2014, 350, 1-9. [CrossRef]

10. Chakraborty, S.; Basak, T. Numerical analysis of electron density and response time delay during solar flares in mid-latitudinal lower ionosphere. Astrophys. Space. Sci. 2020, 365, 184. [CrossRef]

11. Gil, A.; Modzelewska, R.; Moskwa, S.; Siluszyk, A.; Siluszyk, M.; Wawrzynczak, A.; Pozoga, M.; Tomasik, L. The Solar Event of 14-15 July 2012 and Its Geoeffectiveness. Sol. Phys. 2020, 295, 135. [CrossRef]

12. Curto, J.J.; Juan, J.M.; Timoté, C.C. Confirming geomagnetic Sfe by means of a solar flare detector based on GNSS. J. Space Weather Space Clim. 2019, 9, A42. [CrossRef]

13. Srećković, V.; Šulić, D.; Vujičić, V.; Jevremović, D.; Vyklyuk, Y. The effects of solar activity: Electrons in the terrestrial lower ionosphere. J. Geograph. Inst. Cvijic 2017, 67, 221-233. [CrossRef]

14. Nina, A.; Čadež, V.M.; Popović, L.Č.; Srećković, V.A. Diagnostics of plasma in the ionospheric D-region: Detection and study of different ionospheric disturbance types. Eur. Phys. J. D 2017, 71, 189. [CrossRef]

15. An, X.; Meng, X.; Chen, H.; Jiang, W.; Xi, R.; Chen, Q. Modelling Global Ionosphere Based on Multi-Frequency, Multi-Constellation GNSS Observations and IRI Model. Remote Sens. 2020, 12, 439. [CrossRef]

16. Benevides, P.; Nico, G.; Catalão, J.; Miranda, P.M.A. Analysis of Galileo and GPS Integration for GNSS Tomography. IEEE Trans. Geosci. Remote Sens. 2017, 55, 1936-1943. [CrossRef]

17. Mateus, P.; Tomé, R.; Nico, G.; Catalão, J. Three-Dimensional Variational Assimilation of InSAR PWV Using the WRFDA Model. IEEE Trans. Geosci. Remote Sens. 2016, 54, 7323-7330. [CrossRef]

18. Zhao, J.; Zhou, C. On the optimal height of ionospheric shell for single-site TEC estimation. GPS Solut. 2018, 22, 48. [CrossRef]

19. Scherliess, L.; Schunk, R.W.; Sojka, J.J.; Thompson, D.C.; Zhu, L. Utah State University Global Assimilation of Ionospheric Measurements Gauss-Markov Kalman filter model of the ionosphere: Model description and validation. J. Geophys. Res. Space 2006, 111, A11315. [CrossRef]

20. Nava, B.; Coïsson, P.; Radicella, S. A new version of the NeQuick ionosphere electron density model. J. Atmos. Sol.-Terr. Phys. 2008, 70, 1856-1862. [CrossRef]

21. Nina, A.; Nico, G.; Odalović, O.; Čadež, V.; Drakul, M.T.; Radovanović, M.; Popović, L.Č. GNSS and SAR Signal Delay in Perturbed Ionospheric D-Region During Solar X-Ray Flares. IEEE Geosci. Remote Sens. Lett. 2020, 17, 1198-1202. [CrossRef]

22. Frissell, N.A.; Vega, J.S.; Markowitz, E.; Gerrard, A.J.; Engelke, W.D.; Erickson, P.J.; Miller, E.S.; Luetzelschwab, R.C.; Bortnik, J. High-Frequency Communications Response to Solar Activity in September 2017 as Observed by Amateur Radio Networks. Space Weather 2019, 17, 118-132. [CrossRef]

23. Martucci, G.; Navas-Guzman, F.; Renaud, L.; Romanens, G.; Gamage, S.M.; Hervo, M.; Jeannet, P.; Haefele, A. Validation of temperature data from the RAman Lidar for Meteorological Observations (RALMO) at Payerne. An application to liquid cloud supersaturation. Atmos. Meas. Tech. Discuss. 2020, 2020, 1-32. [CrossRef] 